\title{
Integrative Bioinformatics Analysis of KPNA2 in Six Major Human Cancers
}

\section{Ming Liu ( $\nabla \times$ 53now@163.com )}

Lishui People's Hospital

Chaobo Xiu

Lishui People's Hosptial

Research article

Keywords: KPNA2, bioinformatics, cancer, prognosis

Posted Date: September 8th, 2020

DOI: https://doi.org/10.21203/rs.3.rs-60450/v1

License: (a) (i) This work is licensed under a Creative Commons Attribution 4.0 International License. Read Full License 


\section{Abstract \\ Background}

Malignant tumors were considered as the leading causes of mortality globally. More and more studies found that dysregulated genes played an important role in the carcinogenesis. The aim of this study was to explore the significance of KPNA2 in human five major cancers including non-small cell lung cancer (NSCLC), gastric cancer, colorectal cancer, breast cancer, hepatocellular carcinoma and bladder cancer based on bioinformatics analysis.

\section{Methods}

The data were collected and comprehensive analyzed based on multiple databases. KPNA2 mRNA expression in 6 major cancers were investigated in Oncomine, the human protein atlas and GEPIA databases. The mutation status of KPNA2 in the 6 major cancers were evaluated by online data analysis tool Catalog of Somatic Mutations in Cancer (COSMIC) and cBioPortal. Co-expressed genes with KPNA2 were identified by using LinkedOmics and made pairwise correlation by Cancer Regulome tools. Proteinprotein interaction (PPI) network relevant to KPNA2 was constructed by STRING database and KEGG pathway of the included proteins of the PPI network was explored and demonstrated by circus plot. Survival analysis relevant KPNA2 of the 6 cancers were performed by GEPIA online data analysis tool based on TCGA database.

\section{Results}

Compared with paired normal tissue, KPNA2 mRNA was up-regulated in all of the 6 type cancers. KPNA2 mutations especially missense substitution were widely identified in 6 major cancers and interact with different genes in different cancer types. Genes involved in PPI network were mainly enriched in p53 signaling pathway, cell cycle, viral carcinogenesis, Foxo signaling pathway and et c. KPNA2 protein was mainly localized to the nucleoplasm and cytosol in cancer cells. Immunohistochemistry assay indicated that KPNA2 protein was also positive expressed in nucleoplasm with brownish yellow staining. Overall survival (OS) and progression free survival (PFS) were generally different between KPNA2 high and low expression groups.

\section{Conclusions}

KPNA2 was widely dysregulated and mutated in carcinomas and correlated with the patients prognosis which may be potential target for cancer treatment and biomarker for prognosis.

\section{Background}


Cancer is the leading cause of death globally. According to the cancer statistical analysis in year 2018, it was estimated 9.6 million deaths and 18.1 million new cases of all type cancers[1]. Cancer had posed a heavy burden not only for the human beings but also for the governments and health provides. Lung cancer especially non-small cell lung cancer (NSCLC), gastric cancer, colorectal cancer, breast cancer, liver hepatic cancer and bladder cancer were the most common carcinomas diagnosed clinically with high incidence and mortality $[2,3]$. Although caner had high incidence and poor prognosis, the general carcinogenesis was not clear yet. Recent years, with the development of biology and life science, more and more evidence had been clear that the driving genes had played an import role in the carcinogenesis and pathways[4]. The driving genes including oncogenes and tumor suppressor genes may involve in the cell division, apoptosis[5], proliferation[6], migration which may act as the general phenotype of malignant carcinoma.

Karyopherin subunit alpha 2 (KPNA2) is one of the important members of karyophenin family[7]. It has three functional domains: $\mathrm{N}$-terminal Importin $\beta$ binding domain, central domain and a short acid $\mathrm{C}$ terminal. The central domain contains the nuclear localization signal (NLS) binding site and CAS binding site $[8,9]$. In the cytoplasm, Karyopherin subunit alpha 2 can recognize and bind nucleophilic NLS, while Importin $\beta$ will combine with karyophenin to form NLS- $\alpha / \beta$ complex, and then enter the nucleus through the nuclear pore complex under the energy provided by RanGTP enzyme[8]. KPNA2 is not expressed or low expressed in normal tissues, but it is up-regulated in some type of carcinoma such as breast cancer[10, 11], ovarian cancer[12]. However, seldom studies focused on the KPNA2 expression, mutation and as prognostic marker for pan-cancer. In the present work, we investigated KPNA2 mRNA expression, mutation and prognostic significance in 6 major carcinomas through well-known online databases.

\section{Methods}

\section{KPNA2 mRNA expression analysis}

KPNA2 mRNA expression level of human normal tissues and multiple cancers were identified in the human protein atlas database(https://www.proteinatlas.org/) with data original from HPA, GTEx and FANTOM5 project. KPNA2 mRNA expression level between cancer tissue and paired normal tissue was further validated by Oncomine database[13] and GEPIA online data analysis tool with data original form the TCGA database.

\section{KPNA2 gene mutation analysis}

KPNA2 gene mutation was analyzed through the cBio cancer genomics portal (http://cbioportal.org) with the data origin from the TCGA database. The mutation frequency of nonsense substitution, missense substitution, synonymous substitution, inframe insertion, frameshift and et c. were identified and expressed by pie plot. The single nucleotide mutation of KPNA2 mRNA was also screened by catalogue of somatic mutation in cancer (COSMIC) (https://cancer.sanger.ac.uk/cosmic/) online data analysis tool[14]. 


\section{Genome-wide Association of KPNA2 mRNA in Cancer analysis}

The expression of KPNA2 gene and its correlation with other genes of the 6 cancer types were expressed by the circus plots generated from the Cancer Regulome tools and data (http://explorer.cancerregulome.org/). Co-expressed genes were clustered and demonstrated by the heat map generated from LinkedOmics database (http://www.linkedomics.org/login.php)[15]. The top positive and negative correlated genes with KPNA2 was identified and made Pearson correlations test.

\section{PPI network construction and KEGG path way enrichment}

The protein-protein interaction(PPI) network relevant to KPNA2 was constructed by the STRINIG database(http://string-db.org/cgi/input.pl)[16]. The genes included in the PPI network were identified and make KEGG pathway enrichment demonstrated by circus plot.

\section{Survival analysis}

According to the median expression level of KPNA2 mRNA, cancer patients were divided in to high expression(>=median expression) group and low expression group. The progression free survival(PFS) and overall survival (OS) were compared between the high and low expression group of the 6 cancer types and demonstrated by survival curve[17].

\section{KPNA2 protein expression analysis}

KPNA2 protein expression in tumor cell lines and cancer tissues were detected by immunofluorescent staining and immunohistochemistry assay in the human protein atlas database(https://www.proteinatlas.org/).

\section{Data analysis}

The data was analyzed based on the relevant databases or online data analysis tool.

\section{Results}

\section{KPNA2 mRNA expression in normal and tumor tissue}

KPNA2 mRNA expression in all human body tissues were demonstrated in Figure 1A. The expression level was quite different across tissue. KPNA2 mRNA expression levels in different type cancers were showed in Figure 1B, which indicated that the expression level across different cancers were not obviously different. KPNA2 was up-regulated in cancer tissue compared with paired normal tissue in all the 6 major cancers based on Oncomine database (Figure 1C) and GEPIA with statistical difference $(p<0.05)$ (Figure 2).

\section{KPNA2 mutation analysis}


KPNA2 mutation status was analysis of the 6 major cancers were evaluated by online data analysis tool Catalog of Somatic Mutations in Cancer (COSMIC) and cBioPortal. KPNA2 mutations were widely identified in 6 major cancers and interact with different genes in different cancer types. Missense substitution were found in lung cancer(84.21\%), gastric cancer(48.15\%), colorectal cancer (46.94\%), breast cancer(30.43\%), liver hepatic cancer(38.46\%) and bladder cancer (87.50\%). Other major mutation including nonsense substitution and synonymous substitution were also identified in the 6 major cancers (Figure 3A). For pan cancers analysis, KPNA2 highly mutated in uterine carcinoma, stomach cancer, cervical cancer, breast cancer and et c. based on TCGA database, Figure 3B. For single nucleotide mutation, $\mathrm{C}>\mathrm{T}$ and $\mathrm{G}>\mathrm{T}$ were most common in the KPNA2 coding strand, both of which were identified in the 6 major cancer types. And other kind of single nucleotide mutations were rare in TCGA cancer samples of the 6 cancer types, Figure 4.

\section{Genome-wide Association of KPNA2 in Cancer}

Based on the association among genes, DNA methylation, somatic copy number, somatic mutation and protein level, circus plots were drawn to display the interrelation between KPNA2 and other genes. According to the data from TCGA, KPNA2 was associated with other genes that could be detected in NSCLC, gastric cancer, colorectal cancer, liver hepatic cancer and bladder cancer, Figure 5.

\section{Co-expressed genes with KPAN2 in 6 major cancers}

The co-expressed genes with KPAN2 in 6 major cancers was demonstrated with the heat map, Figure 6. The top positive and negative correlated gens with KPAN2 in 6 major cancers was showed in Figure 7.

\section{PPI network of KPNA2}

Twenty genes were included in the PPI network with the edges of 105 and local clustering coefficient of 0.713 , which indicated that the PPI enrichment obviously with statistical difference $(p<0.001)$, Figure 8 .

\section{KEGG pathway relevant KPNA2}

Genes that involved in PPI network were mainly enriched in p53 signaling pathway, cell cycle, viral carcinogenesis, Foxo signaling pathway and et c. Figure 9.

\section{KPNA2 mRNA level and patients' prognosis}

Overall survival (OS) was statistical different between KPNA2 mRNA high and low expression groups in NSCLC (HR=1.2, $P<0.05)$, colorectal cancer $(H R=0.51, p<0.01)$, liver hepatic carcinoma $(H R=2.1, p<0.001)$, Figure 10. For disease free survival(DFS), the statistical difference was observed in gastric cancer $(H R=0.67, p<0.05)$ and liver hepatic cancer $(H R=1.9, p<0.001)$, Figure 11.

\section{KPNA2 protein expression}


KPNA2 protein was mainly localized to the nucleoplasm and cytosol in cancer cells detected by immunofluorescence assay, Figure 12. Immunohistochemistry assay indicated that KPNA2 protein was also positive expressed in nucleoplasm with Brownish yellow staining, Figure 13.

\section{Discussion}

The structural nuclear transporter family of KPNA2 includes the input protein family and the output protein family[18]. It mainly mediates proteins with molecular weight greater than $40 \mathrm{kDa}$ through nuclear pore complexes (NPC). The input protein family includes karyophenin a family and import $\beta$ family. There are seven members in karyophenin a family, of which karyophenin a 2 (KPNA2) is one of the most important members. KPNA2 gene is located in chromosome 17q23-q24 in human being, and its encoded protein contains 529 amino acids, with a molecular weight of $58 \mathrm{kDa}[9,19]$. The $\mathrm{N}$-terminal is the Importin $\beta$ binding domain, which has self inhibition function, so that kpna2 can only bind to Importin at the same time $\beta$ and cargo molecules can only be translocated to the nucleus[20,21]; the central region is composed of 10 arm repeat sequences, including 2 NLS binding sites, which can bind to the nucleoprotein with NLS, and the 10th arm sequence can bind to CAS, which is responsible for kpna2 nucleoplasm recycling; the function of C-terminal is not completely clear yet, Fig. 14A.

The classical nuclear protein input is regulated by heterodimer composed of importin $\beta$ and karyophenin a. Karyophenin a protein can recognize and bind NLS of cargo protein. Importin $\beta$ brings the complex composed of karyophenin a and nucleoprotein into the nucleus through NPC, and combines with RanGTP to form protein complex in the nucleus, so as to release karyophenin a and nucleoprotein into the nucleus, and then importin $\beta$ returns directly to the cytoplasm, while karyophenin a returns to the cytoplasm with the help of CAS[22], Fig. 14B.

KPNA2 is a member of the karyopherin family. Given its function in nucleocytoplasmic transport, KPNA2 mediates the translocation of various proteins and is involved in numerous cellular processes, such as cellular differentiation, proliferation and apoptosis, transcriptional regulation, immune response, and viral infection. Several studies have recently demonstrated that KPNA2 is up-regulated in multiple malignancies[23-25]. Its aberrant expression is often associated with adverse outcomes in affected patients, indicating that KPNA2 plays a significant role in carcinogenesis and tumor progression[23, 26, 27]. These findings are supported by previous studies, which reported that KPNA2 may have a functional role in the malignant transformation of cells.

As an intranuclear transporter, kpna2 is involved in cell differentiation, proliferation and apoptosis, transcriptional regulation, immune response and virus infection. More importantly, many studies have found that Pna2 is involved in tumor progression by regulating the nuclear translocation of tumor related proteins. It has been reported that: 1) kpna2 is involved in the nuclear translocation of many tumor related transcription factors, including E2F1 and pleomorphic adenoma, two members of the zinc finger plag family Gene1, plag1)[28] and lot1[29] and BTB/POZ transcription factor kaiso[30], etc.; 2) kpna2 mediates Rac-1 nuclear translocation[31], Rac-1 participates in tumor formation by participating in cell 
cycle, cell adhesion and migration; 3) kpna2 mediates the entry of cell cycle regulatory protein CHK2 into the nucleus, and overexpression of kpna2 leads to increased nuclear input of CHK2[32]; 4) kpna2 participates in breast cancer suppression BRCA1 has the function of DNA repair and cell cycle monitoring, which affects the process of tumor formation; 5) kpna2 participates in the entry of NBS1, which is a kind of DNA repair complex protein, also involved in tumor formation[33].

In our present work, we noticed that KPNA2 mRNA was up-regulated in all of the 6 type cancers compared with paired normal tissue. KPNA2 mutations especially missense substitution were widely identified in 6 major cancers and interact with different genes in different cancer types. Genes involved in PPI network were mainly enriched in p53 signaling pathway, cell cycle, viral carcinogenesis and Foxo signaling pathway. Immunohistochemistry assay indicated that KPNA2 protein was also positive expressed in nucleoplasm with brownish yellow staining. Overall survival (OS) and progression free survival (PFS) were generally different between KPNA2 high and low expression groups, which may be a potential biomarker for cancer prognosis.

\section{Conclusions}

KPNA2, as an intranuclear transport protein, participates in a variety of biological activities through the transport function of nucleoplasm, and its role in tumor development has attracted more and more attention. In view of the abnormal expression of KPNA2 in most cancer tissues and serum of the cancer patients, and related to the proliferation, migration and invasion of tumor cells, KPNA2 can be used as a potential biomarker for prognosis. However, the mechanism of KPNA2 in tumorigenesis and progression are not complete clear yet and needs further investigation.

\section{Abbreviations}

NSCLC: Non-small cell lung cancer; COSMIC:Catalog of Somatic Mutations in Cancer; PPI:Protein-protein interaction; OS:Overall survival; PFS:Progression free survival; KPNA2:Karyopherin subunit alpha 2; NLS:nuclear localization signal;

\section{Declarations}

\section{Acknowledgements}

We thank all staffs of our department who involved in this work.

\section{Authors' contributions}

Ming Liu designed the experiment; Chaobo Xu did the work. Chaobo Xu \& Ming Liu prepared the manuscript together.

\section{Funding}


None

\section{Availability of data and materials}

All data generated or analyzed is this study are available at the relevant database or contacting the corresponding author.

\section{Ethics approval and consent to participate}

This work is a bioinformatics analysis based on database mining.

\section{Consent for publication}

All authors agree to submit and publish the work in BMC cancer

\section{Competing interests}

The authors declare that there are no conflicts of interest.

\section{References}

1. Bray F, Ferlay J, Soerjomataram I, Siegel RL, Torre LA, Jemal A. Global cancer statistics 2018: GLOBOCAN estimates of incidence and mortality worldwide for 36 cancers in 185 countries. CA Cancer J Clin. 2018;68:394-424.

2. Siegel RL, Miller KD, Jemal A. Cancer statistics, 2019. CA Cancer J Clin. 2019;69:7-34.

3. Siegel RL, Miller KD, Jemal A. Cancer statistics, 2020. CA Cancer J Clin. 2020;70:7-30.

4. Johnson LA, June $\mathrm{CH}$. Driving gene-engineered T cell immunotherapy of cancer. Cell Res. 2017;27:38-58.

5. Zhang KJ, Qian J, Wang SB, Yang Y. Targeting Gene-Viro-Therapy with AFP driving Apoptin gene shows potent antitumor effect in hepatocarcinoma. J Biomed Sci. 2012;19:20.

6. Cui Y, Zhang C, Ma S, Guo W, Cao W, Guan F. CASC5 is a potential tumour driving gene in lung adenocarcinoma. Cell Biochem Funct 2020.

7. Kelley JB, Talley AM, Spencer A, Gioeli D, Paschal BM. Karyopherin alpha7 (KPNA7), a divergent member of the importin alpha family of nuclear import receptors. BMC Cell Biol. 2010;11:63.

8. Yasuhara N, Kumar PK. Aptamers that bind specifically to human KPNA2 (importin-a1) and efficiently interfere with nuclear transport. J Biochem. 2016;160:259-68.

9. Dörr SN, Schlicker MN, Hansmann IN. Genomic structure of karyopherin alpha2 (KPNA2) within a low-copy repeat on chromosome 17q23-q24 and mutation analysis in patients with Russell-Silver syndrome. Hum Genet. 2001;109:479-86.

10. Alshareeda AT, Negm OH, Green AR, Nolan CC, Tighe P, Albarakati N, Sultana R, Madhusudan S, Ellis IO, Rakha EA. KPNA2 is a nuclear export protein that contributes to aberrant localisation of key 
proteins and poor prognosis of breast cancer. Br J Cancer. 2015;112:1929-37.

11. Dankof A, Fritzsche FR, Dahl E, Pahl S, Wild P, Dietel M, Hartmann A, Kristiansen G. KPNA2 protein expression in invasive breast carcinoma and matched peritumoral ductal carcinoma in situ. Virchows Arch. 2007;451:877-81.

12. Huang L, Zhou Y, Cao XP, Lin JX, Zhang L, Huang ST, Zheng M. KPNA2 is a potential diagnostic serum biomarker for epithelial ovarian cancer and correlates with poor prognosis. Tumour Biol. 2017;39:1010428317706289.

13. Rhodes DR, Yu J, Shanker K, Deshpande N, Varambally R, Ghosh D, Barrette T, Pandey A, Chinnaiyan AM. ONCOMINE: a cancer microarray database and integrated data-mining platform. Neoplasia. 2004;6:1-6.

14. Li QT, Huang ZZ, Chen YB, Yao HY, Ke ZH, He XX, Qiu MJ, Wang MM, Xiong ZF, Yang SL. Integrative Analysis of Siglec-15 mRNA in Human Cancers Based on Data Mining. J Cancer. 2020;11:2453-64.

15. Vasaikar SV, Straub P, Wang J, Zhang B. LinkedOmics: analyzing multi-omics data within and across 32 cancer types. Nucleic Acids Res. 2018;46:D956-63.

16. Szklarczyk D, Gable AL, Lyon D, Junge A, Wyder S, Huerta-Cepas J, Simonovic M, Doncheva NT, Morris JH, Bork P, Jensen LJ, Mering CV. STRING v11: protein-protein association networks with increased coverage, supporting functional discovery in genome-wide experimental datasets. Nucleic Acids Res. 2019;47:D607-13.

17. Tang Z, Li C, Kang B, Gao G, Li C, Zhang Z. GEPIA: a web server for cancer and normal gene expression profiling and interactive analyses. Nucleic Acids Res. 2017;45:W98-102.

18. Fagerberg L, Hallström BM, Oksvold P, Kampf C, Djureinovic D, Odeberg J, Habuka M, Tahmasebpoor S, Danielsson A, Edlund K, Asplund A, Sjöstedt E, Lundberg E, Szigyarto CA, Skogs M, Takanen JO, Berling H, Tegel H, Mulder J, Nilsson P, Schwenk JM, Lindskog C, Danielsson F, Mardinoglu A, Sivertsson A, von FK, Forsberg, Zwahlen M, Olsson M, Navani I, Huss S, Nielsen M, Ponten J, Uhlén F. M. Analysis of the human tissue-specific expression by genome-wide integration of transcriptomics and antibody-based proteomics. Mol Cell Proteomics. 2014;13:397-406.

19. Mai M, Qian C, Yokomizo A, Smith DI, Liu W. Cloning of the human homolog of conductin (AXIN2), a gene mapping to chromosome 17q23-q24. Genomics. 1999;55:341-4.

20. Zu YL, Ai Y, Huang CK. Characterization of an autoinhibitory domain in human mitogen-activated protein kinase-activated protein kinase 2. J Biol Chem. 1995;270:202-6.

21. Chook YM, Blobel G. Karyopherins and nuclear import. Curr Opin Struct Biol. 2001;11:703-15.

22. Goldfarb DS, Corbett AH, Mason DA, Harreman MT, Adam SA. Importin alpha: a multipurpose nuclear-transport receptor. Trends Cell Biol. 2004;14:505-14.

23. Zhou J, Dong D, Cheng R, Wang Y, Jiang S, Zhu Y, Fan L, Mao X, Gui Y, Li Z, Li X, Shi B. Aberrant expression of KPNA2 is associated with a poor prognosis and contributes to OCT4 nuclear transportation in bladder cancer. Oncotarget. 2016;7:72767-76.

24. Takada T, Tsutsumi S, Takahashi R, Ohsone K, Tatsuki H, Suto T, Kato T, Fujii T, Yokobori T, Kuwano H. KPNA2 over-expression is a potential marker of prognosis and therapeutic sensitivity in colorectal 
cancer patients. J Surg Oncol. 2016;113:213-7.

25. Li XL, Jia LL, Shi MM, Li X, Li ZH, Li HF, Wang EH, Jia XS. Downregulation of KPNA2 in non-small-cell lung cancer is associated with Oct4 expression. J Transl Med. 2013;11:232.

26. Shi B, Su B, Fang D, Tang Y, Xiong G, Guo Z, He Q, Yang X, Zhao W, Guo Y, Li X, Zhou L. High expression of KPNA2 defines poor prognosis in patients with upper tract urothelial carcinoma treated with radical nephroureterectomy. BMC Cancer. 2015;15:380.

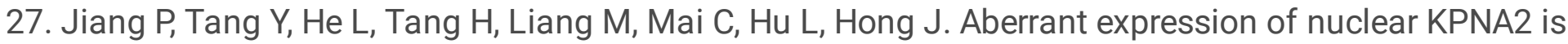
correlated with early recurrence and poor prognosis in patients with small hepatocellular carcinoma after hepatectomy. Med Oncol. 2014;31:131.

28. Braem CV, Kas K, Meyen E, Debiec-Rychter M, Van De Ven WJ, Voz ML. Identification of a karyopherin alpha 2 recognition site in PLAG1, which functions as a nuclear localization signal. J Biol Chem. 2002;277:19673-8.

29. Huang SM, Huang SP, Wang SL, Liu PY. Importin alpha1 is involved in the nuclear localization of Zac1 and the induction of p21WAF1/CIP1 by Zac1. Biochem J. 2007;402:359-66.

30. Kelly KF, Otchere AA, Graham M, Daniel JM. Nuclear import of the BTB/POZ transcriptional regulator Kaiso. J Cell Sci. 2004;117:6143-52.

31. Sandrock K, Bielek H, Schradi K, Schmidt G, Klugbauer N. The nuclear import of the small GTPase Rac1 is mediated by the direct interaction with karyopherin alpha2. Traffic. 2010;11:198-209.

32. Zannini L, Lecis D, Lisanti S, Benetti R, Buscemi G, Schneider C, Delia D. Karyopherin-alpha2 protein interacts with Chk2 and contributes to its nuclear import. J Biol Chem. 2003;278:42346-51.

33. Tseng SF, Chang CY, Wu KJ, Teng SC. Importin KPNA2 is required for proper nuclear localization and multiple functions of NBS1. J Biol Chem. 2005;280:39594-600.

\section{Figures}



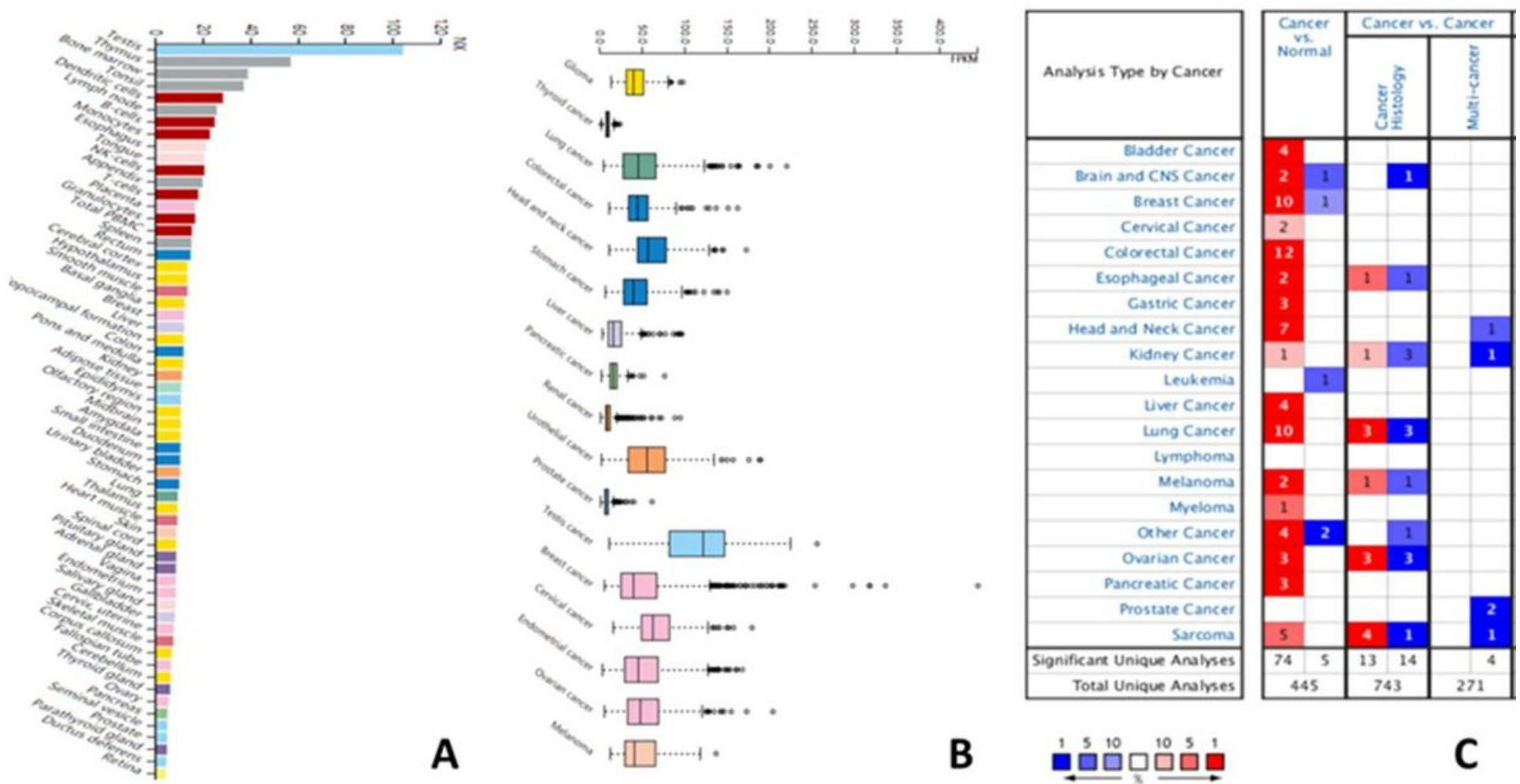

Figure 1

KPNA2 expression analysis (A: KPNA2 expression in across human body tissues; B: KPNS2 expression across carcinomas; D: KPNA2 expression between cancer tissue and paired normal tissues based on oncoming database) 

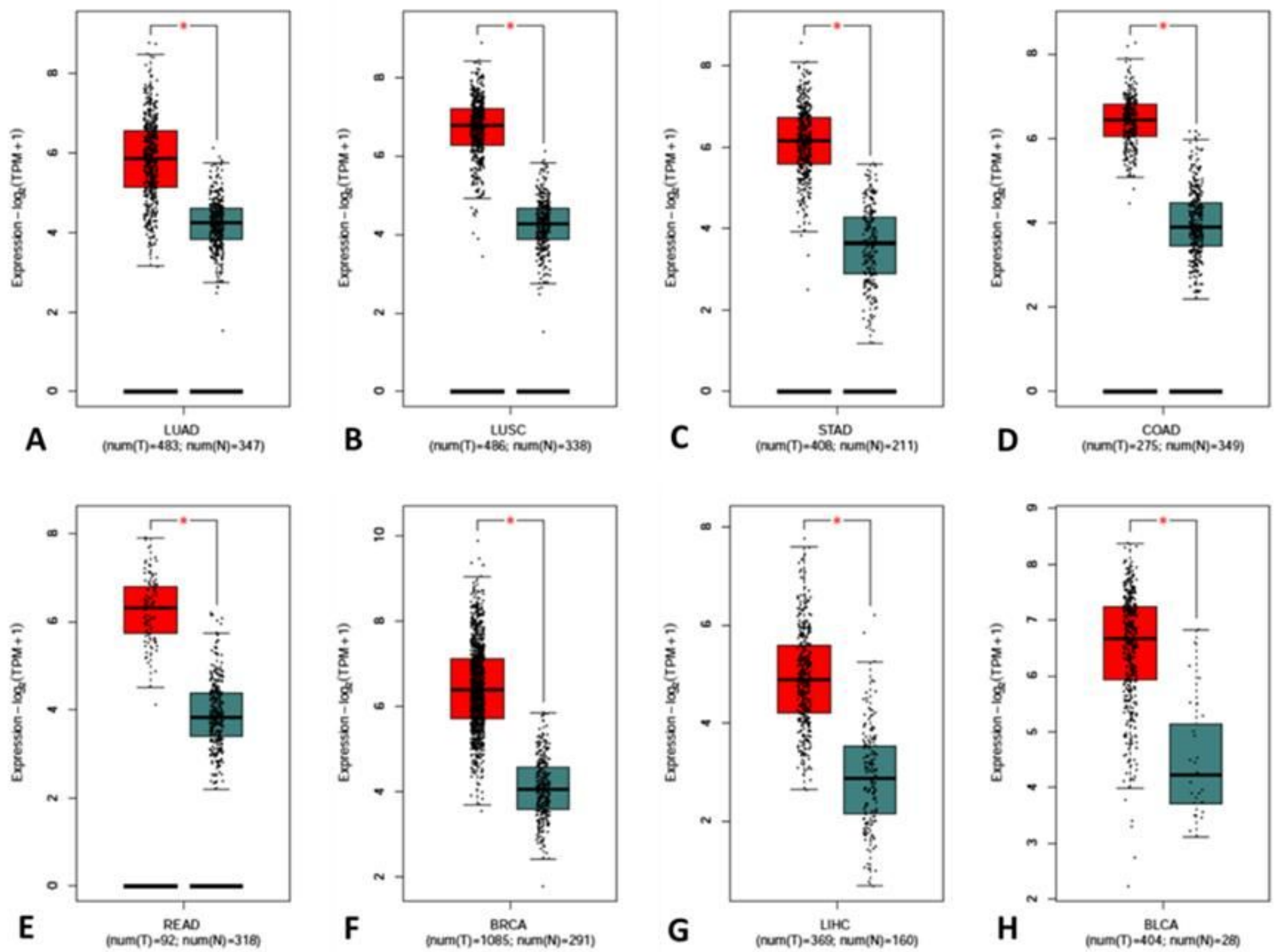

Figure 2

Scatter plot of KPNA2 mRNA expression between paired normal tissue and cancer tissue (A: Lung adenocarcinoma; $B$ : lung squamous cell carcinoma; C: gastric cancer; D: colon cancer; E:Recal cancer; F: breast cancer; G: hepatocellular carcinoma; H:bladder cancer) 
A
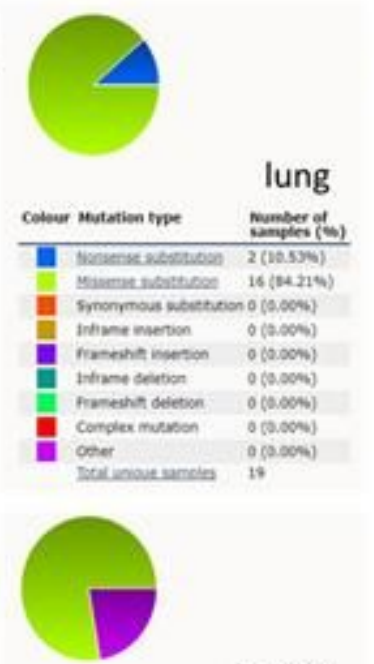

breast

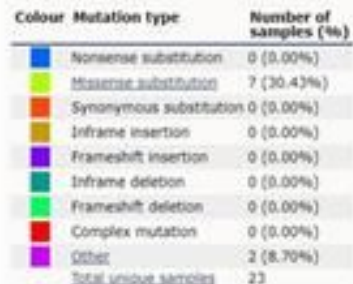

soivesusuneg

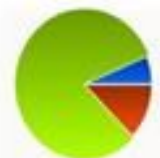

stomach
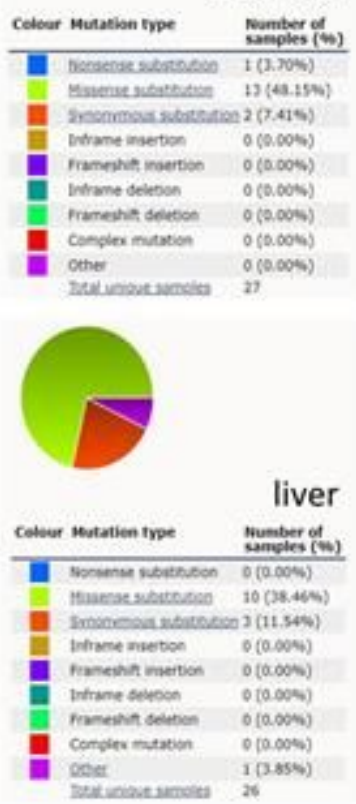

liver sater of

$(0.540)$

(10.000.

(1000)

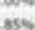

caticias sumola 26

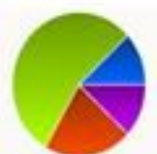

large intestine

\begin{tabular}{|c|c|c|}
\hline & Mutat & $\begin{array}{l}\text { Number of } \\
\text { samples ( }\end{array}$ \\
\hline & 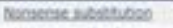 & $5(10.204)$ \\
\hline & 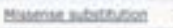 & 23 (46.96k) \\
\hline & 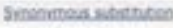 & (18.395) \\
\hline & Drane ivaention & $9(0.00 \mathrm{w})$ \\
\hline & Frameint userson & $0(0,000)$ \\
\hline & Hhreme delebon & $0(0.006)$ \\
\hline & Fianeuint detietion & $0(0,000)$ \\
\hline = & Condiex matation & $0(0,004)$ \\
\hline & gether & $5(10.200)$ \\
\hline & Detungutanded & 49 \\
\hline
\end{tabular}

की

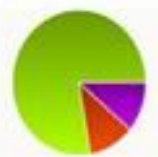

bladder

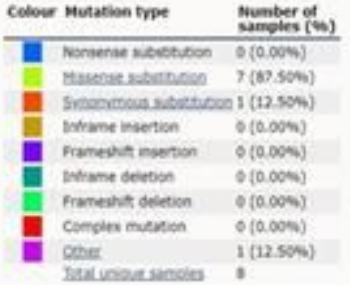

- Deep Deletion

B

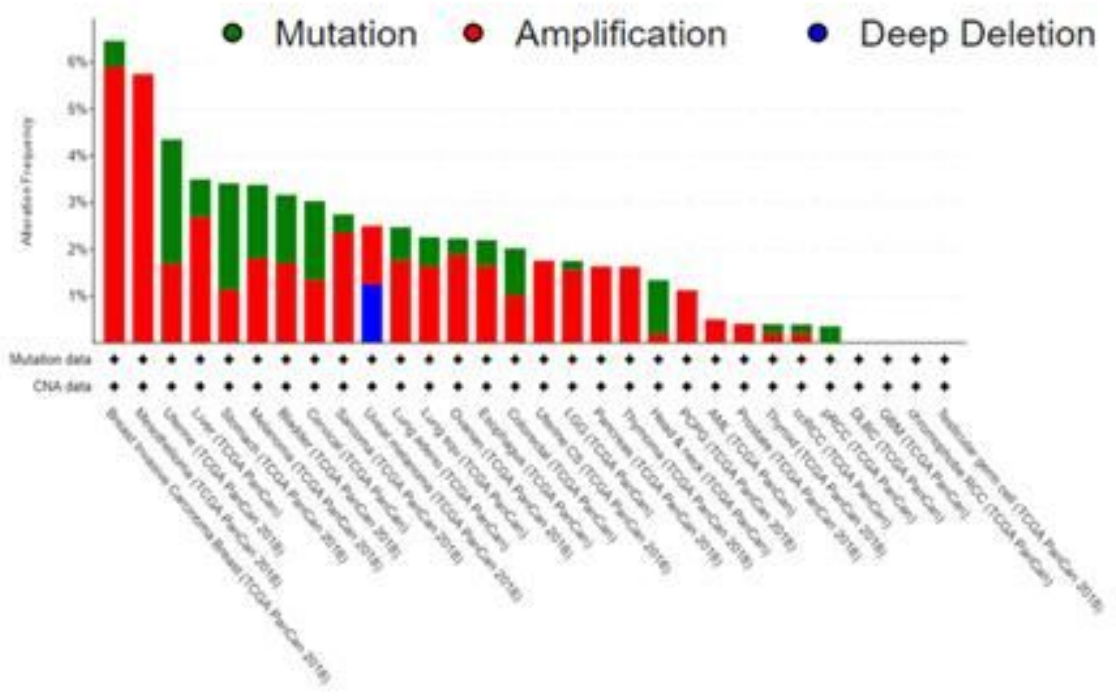

Figure 3

KPNA2 mutation analysis(A: Pie plot of the KPNA2 mutation frequency of the 6 major cancers; $\mathrm{B}$ : Bar chart of KPNA2 mutation in pan cancers based on TCGA database.) 


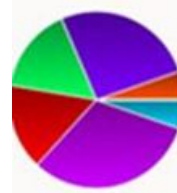

lung

\begin{tabular}{|c|c|c|}
\hline Colour & $\begin{array}{l}\text { Mutation } \\
\text { type }\end{array}$ & $\begin{array}{l}\text { Number of } \\
\text { samples }(\%)\end{array}$ \\
\hline & $A>C$ & $0(0.00 \%)$ \\
\hline & $A>G$ & $0(0.00 \%)$ \\
\hline & $A>I$ & $1(5.56 \%)$ \\
\hline & $C>A$ & $0(0.00 \%)$ \\
\hline & $c>I$ & $5(27.78 \%)$ \\
\hline & $C>C$ & $0(0.00 \%)$ \\
\hline & $\Leftrightarrow>A$ & $3(16.6796)$ \\
\hline & $G>c$ & $3(16.67 \%)$ \\
\hline & $G>I$ & $6(33.33 \%)$ \\
\hline & $I \geqslant A$ & $1(5.56 \%)$ \\
\hline & $T>C$ & $0(0.00 \%)$ \\
\hline & $T>G$ & $0(0.00 \%)$ \\
\hline
\end{tabular}

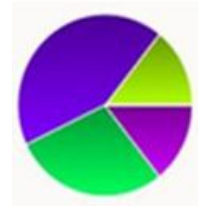

breast
Colour Mutation

\begin{tabular}{ll} 
type & samples $(\%)$ \\
\hline$A>C$ & $0(0.00 \%)$ \\
$A>G$ & $1(14.29 \%)$ \\
$A>T$ & $0(0.00 \%)$ \\
$C>A$ & $0(0.00 \%)$ \\
$C>T$ & $3(42.86 \%)$ \\
$C>G$ & $0(0.00 \%)$ \\
$G>A$ & $2(28.57 \%)$ \\
$G>C$ & $0(0.00 \%)$ \\
$G>T$ & $1(14.29 \%)$ \\
$T>A$ & $0(0.00 \%)$ \\
$T>C$ & $0(0.00 \%)$ \\
$T>G$ & $0(0.00 \%)$ \\
Total unique samples 7
\end{tabular}

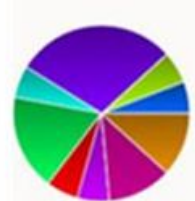

stomach

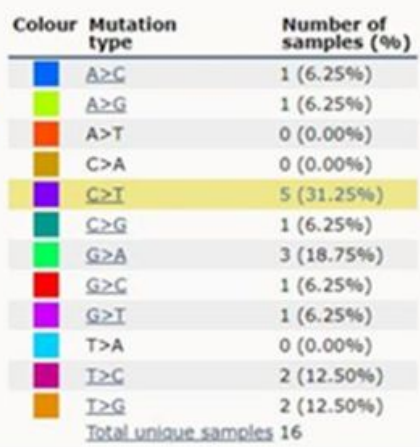

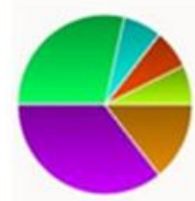

\begin{tabular}{cl}
$\begin{array}{c}\text { Colour } \\
\begin{array}{c}\text { Mutation } \\
\text { type }\end{array}\end{array}$ & $\begin{array}{l}\text { Number of } \\
\text { samples (\%) }\end{array}$ \\
\hline $\mathrm{A}>\mathrm{C}$ & $0(0.00 \%)$ \\
$\mathrm{A}>\mathrm{G}$ & $1(7.69 \%)$ \\
$\mathrm{A}>\mathrm{T}$ & $1(7.69 \%)$ \\
$\mathrm{C}>\mathrm{A}$ & $0(0.00 \%)$ \\
$\mathrm{C}>\mathrm{T}$ & $0(0.00 \%)$ \\
$\mathrm{C}>\mathrm{G}$ & $1(7.69 \%)$ \\
$\mathrm{G}>\mathrm{A}$ & $4(30.77 \%)$ \\
$\mathrm{G}>\mathrm{C}$ & $0(0.00 \%)$ \\
$\mathrm{G}>\mathrm{T}$ & $5(38.46 \%)$ \\
$\mathrm{T}>\mathrm{A}$ & $0(0.00 \%)$ \\
$\mathrm{T}>\mathrm{C}$ & $0(0.00 \%)$ \\
$\mathrm{T}>\mathrm{G}$ & $2(15.38 \%)$ \\
Total uniquesamoles 13
\end{tabular}

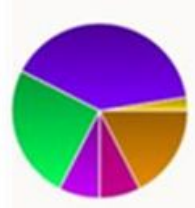

large intestine

\begin{tabular}{ll} 
type & samples (\%) \\
\hline$A>C$ & $0(0.00 \%)$ \\
$A>C$ & $0(0.00 \%)$ \\
$A>T$ & $0(0.00 \%)$ \\
$C>A$ & $1(2.78 \%)$ \\
$C>I$ & $16(44.44 \%)$ \\
$C>C$ & $0(0.00 \%)$ \\
$G>A$ & $10(27.78 \%)$ \\
$G>C$ & $0(0.00 \%)$ \\
$G>T$ & $3(8.33 \%)$ \\
$T>A$ & $0(0.00 \%)$ \\
$I>C$ & $3(8.33 \%)$ \\
$I>G$ & $7(19.44 \%)$
\end{tabular}

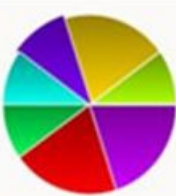

bladder

\begin{tabular}{|c|c|c|}
\hline Colour & $\begin{array}{l}\text { Mutation } \\
\text { type }\end{array}$ & $\begin{array}{l}\text { Number of } \\
\text { samples (\%) }\end{array}$ \\
\hline & $A>C$ & $0(0.00 \%)$ \\
\hline & $A \geq G$ & $1(12.50 \%)$ \\
\hline & $A>T$ & $0(0.00 \%)$ \\
\hline & $C>A$ & $2(25.00 \%)$ \\
\hline & $S \geq I$ & $1(12.50 \%)$ \\
\hline & $6>0$ & $1(12.50 \%)$ \\
\hline & $G>A$ & $1(12.50 \%)$ \\
\hline & $G>C$ & $2(25.00 \%)$ \\
\hline & $G>I$ & $2(25.00 \%)$ \\
\hline & $T>A$ & $0(0.00 \%)$ \\
\hline & $T>C$ & $0(0.0046)$ \\
\hline & $T>G$ & $0(0.00 \%)$ \\
\hline
\end{tabular}

Figure 4

KPNA2 single nucleotide mutation analysis
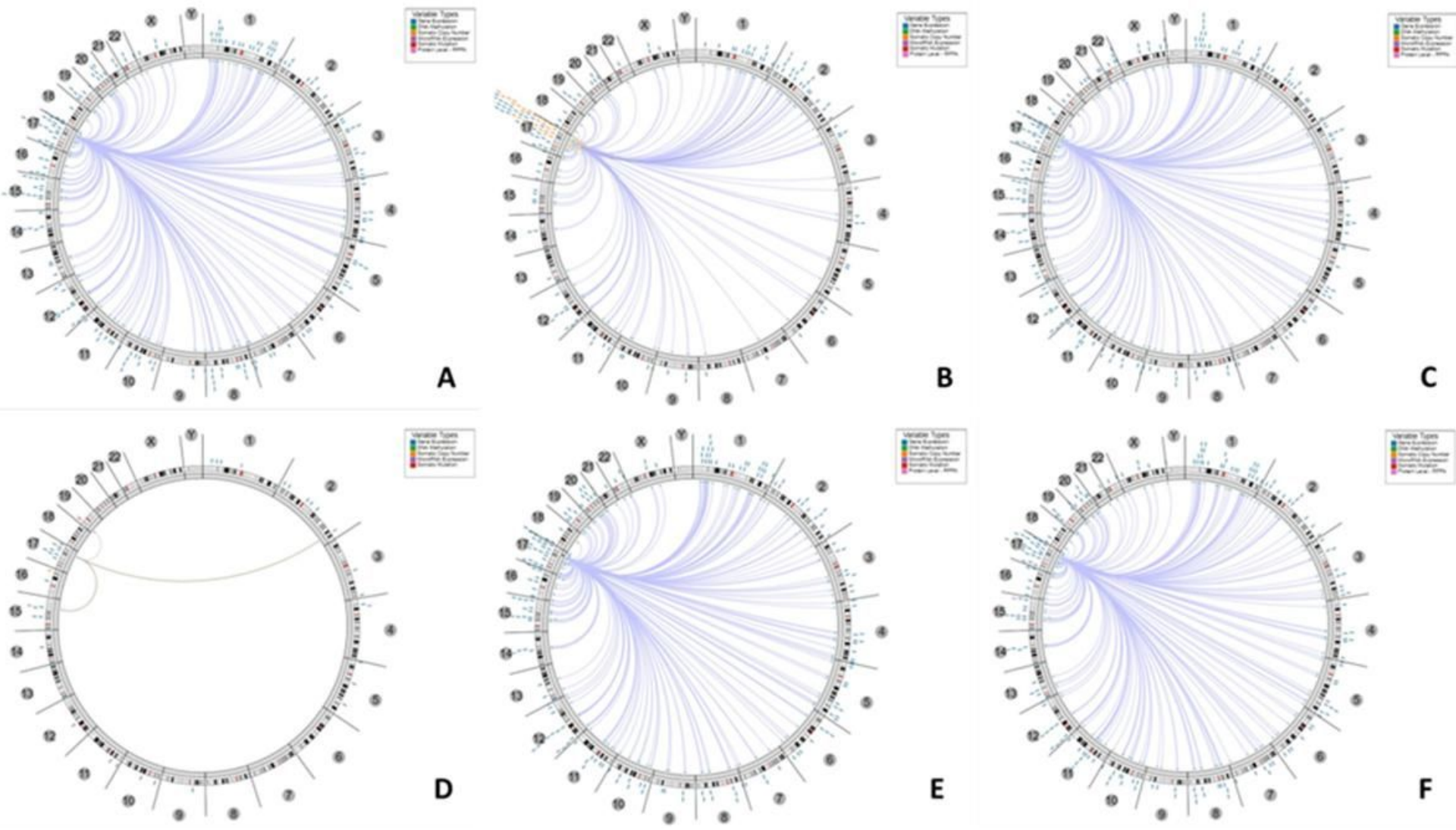

Figure 5 
The circus plot demonstrated the associations between KPNA2 and other genes. The edges in the center connecting the features (with genomic coordinates) displayed around the perimeter. The outer ring displays cytogenetic bands. The inner ring displays associations that contain features lacking genomic coordinates(A: Non-small cell lung cancer; B: Gastric cancer; C: Colorectal cancer; D: Breast cancer; E: Liver hepatic cancer; F: Bladder cancer)

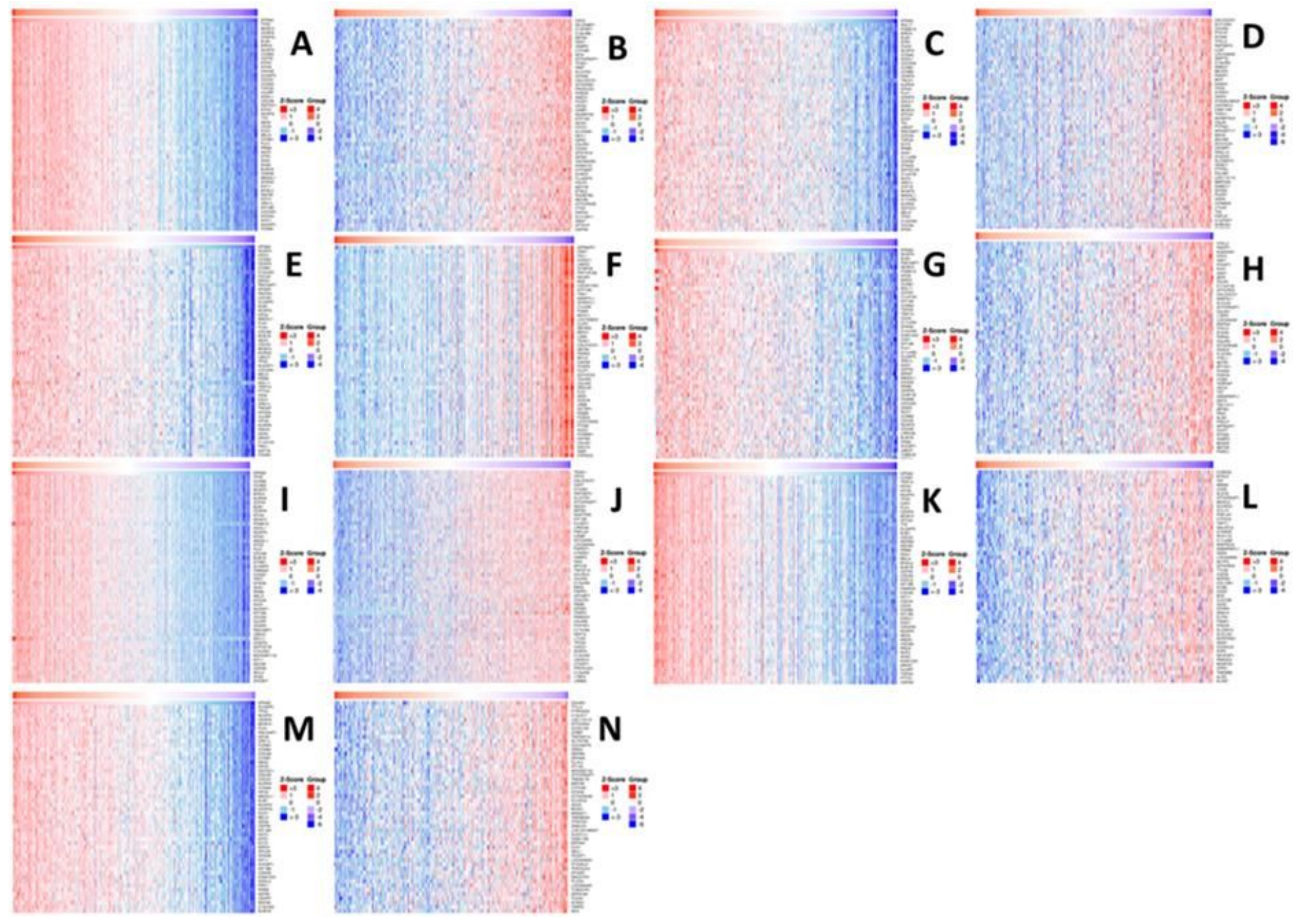

\section{Figure 6}

Heat map of co-expressed genes with KPAN2 in 6 major cancers(A: positive co-expressed genes with KPAN2 in lung adenocarcinoma; B: negative co-expressed genes with KPAN2 in lung adenocarcinoma; C: positive co-expressed genes with KPAN2 in lung squamous carcinoma; D: negative co-expressed genes with KPAN2 in lung squamous carcinoma; $\mathrm{E}$ : positive co-expressed genes with KPAN2 in gastric cancer; $\mathrm{F}$ : negative co-expressed genes with KPAN2 in gastric cancer; G: positive co-expressed genes with KPAN2 in colorectal cancer; $\mathrm{H}$ : negative-expressed genes with KPAN2 in colorectal cancer; I: positive co-expressed genes with KPAN2 in breast cancer; J: negative co-expressed genes with KPAN2 in breast cancer; $\mathrm{K}$ : positive co-expressed genes with KPAN2 in liver hepatic cancer; L: negative co-expressed genes with KPAN2 in breast cancer; M: positive co-expressed genes with KPAN2 in bladder cancer; N: negative coexpressed genes with KPAN2 in bladder cancer) 

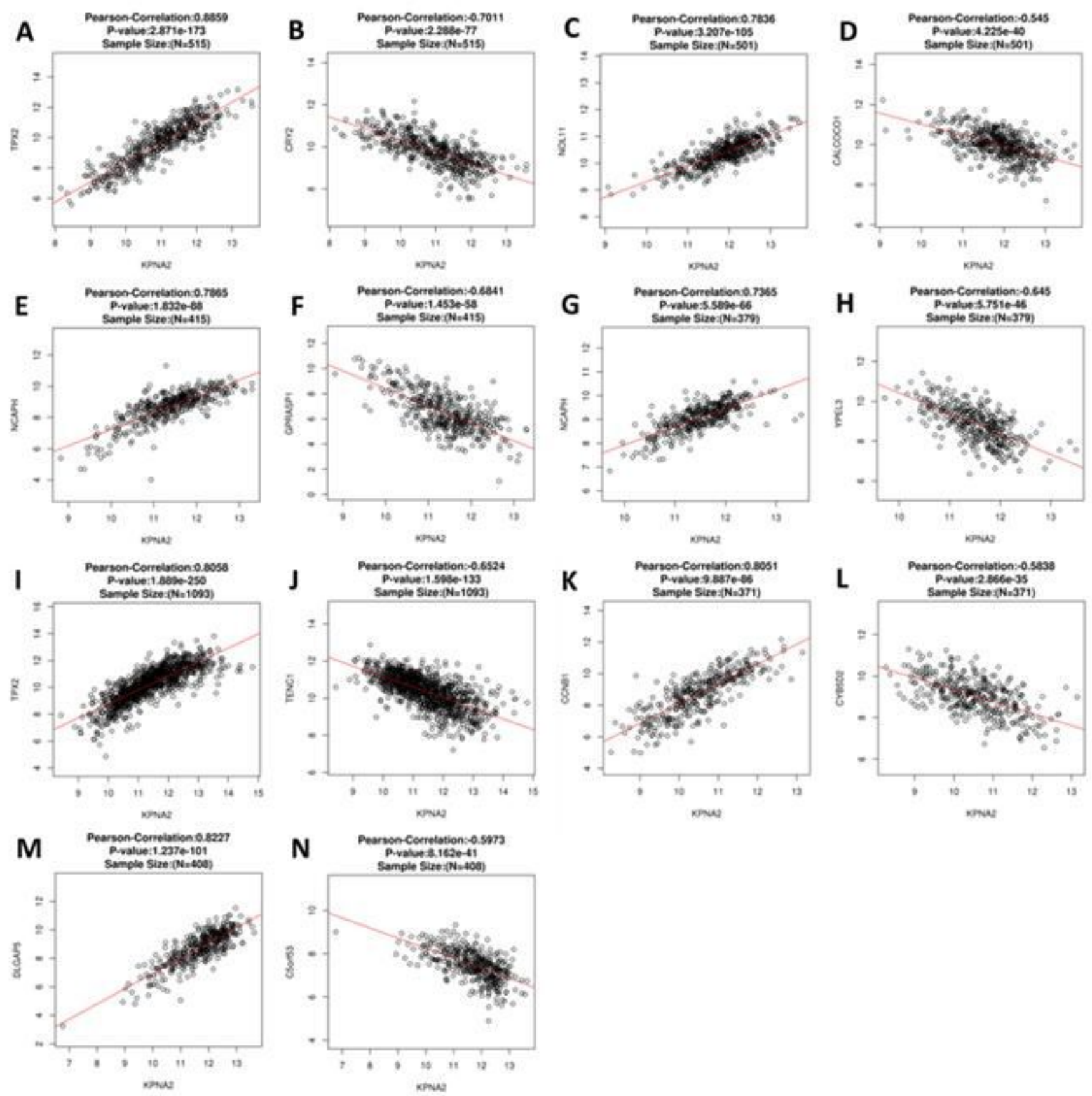

\section{Figure 7}

The top positive and negative correlated gens with KPAN2 in 6 major cancers(A: positive co-expressed genes with KPAN2 in lung adenocarcinoma; B: negative co-expressed genes with KPAN2 in lung adenocarcinoma; C: positive co-expressed genes with KPAN2 in lung squamous carcinoma; D: negative co-expressed genes with KPAN2 in lung squamous carcinoma; $\mathrm{E}$ : positive co-expressed genes with KPAN2 in gastric cancer; F: negative co-expressed genes with KPAN2 in gastric cancer; G: positive coexpressed genes with KPAN2 in colorectal cancer; $\mathrm{H}$ : negative-expressed genes with KPAN2 in colorectal cancer; I: positive co-expressed genes with KPAN2 in breast cancer; J: negative co-expressed genes with KPAN2 in breast cancer; K: positive co-expressed genes with KPAN2 in liver hepatic cancer; L: negative co- 
expressed genes with KPAN2 in breast cancer; M: positive co-expressed genes with KPAN2 in bladder cancer; N: negative co-expressed genes with KPAN2 in bladder cancer)

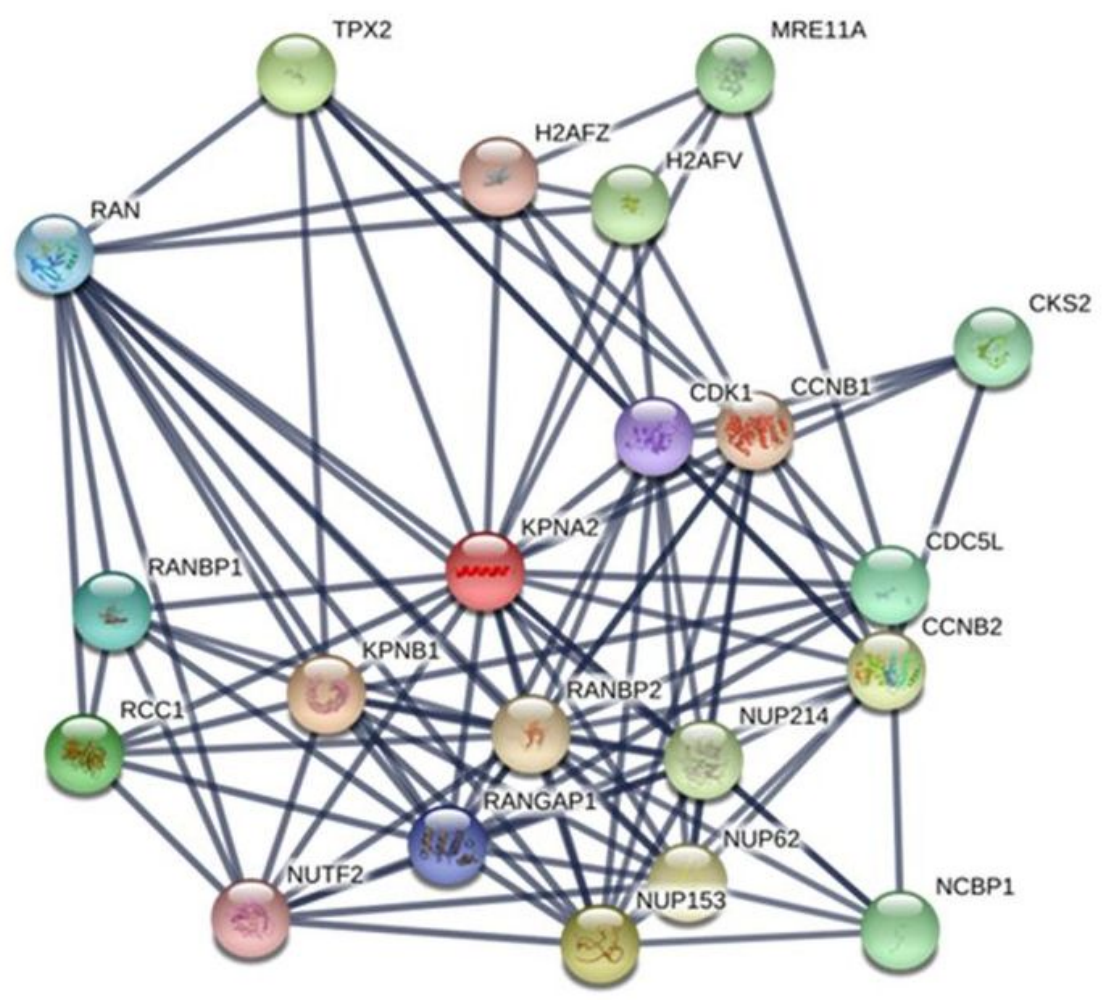

\section{Figure 8}

The PPI network included KPNA2 and relevant gens 


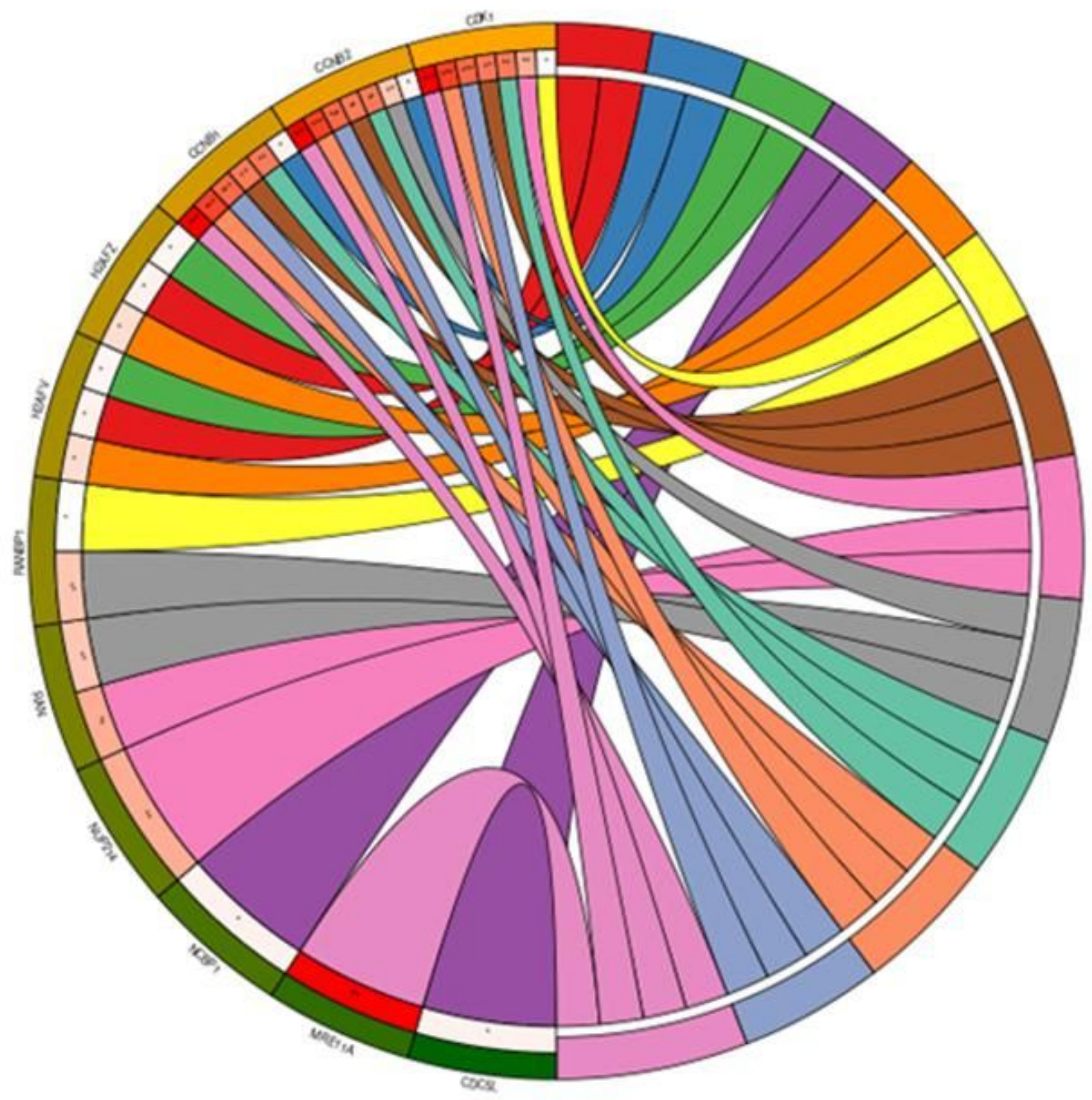

Term

官Alcoholism

官FoxO signaling pathway

卓 Necroptosis

官Sploeosome

Systemic lupus erythematosus

Viral carcinogenesis

官Cell cycle

官 Epstein-Bart virus infection

PHTV.I infection

是 Oocyle meiosis

p53 signaling pathway

Progesterone-mediated oocyle maturatix

Celular senescence

Figure 9

Circus plot of KEGG pathway enrichment of genes that relevant to KPNA2 

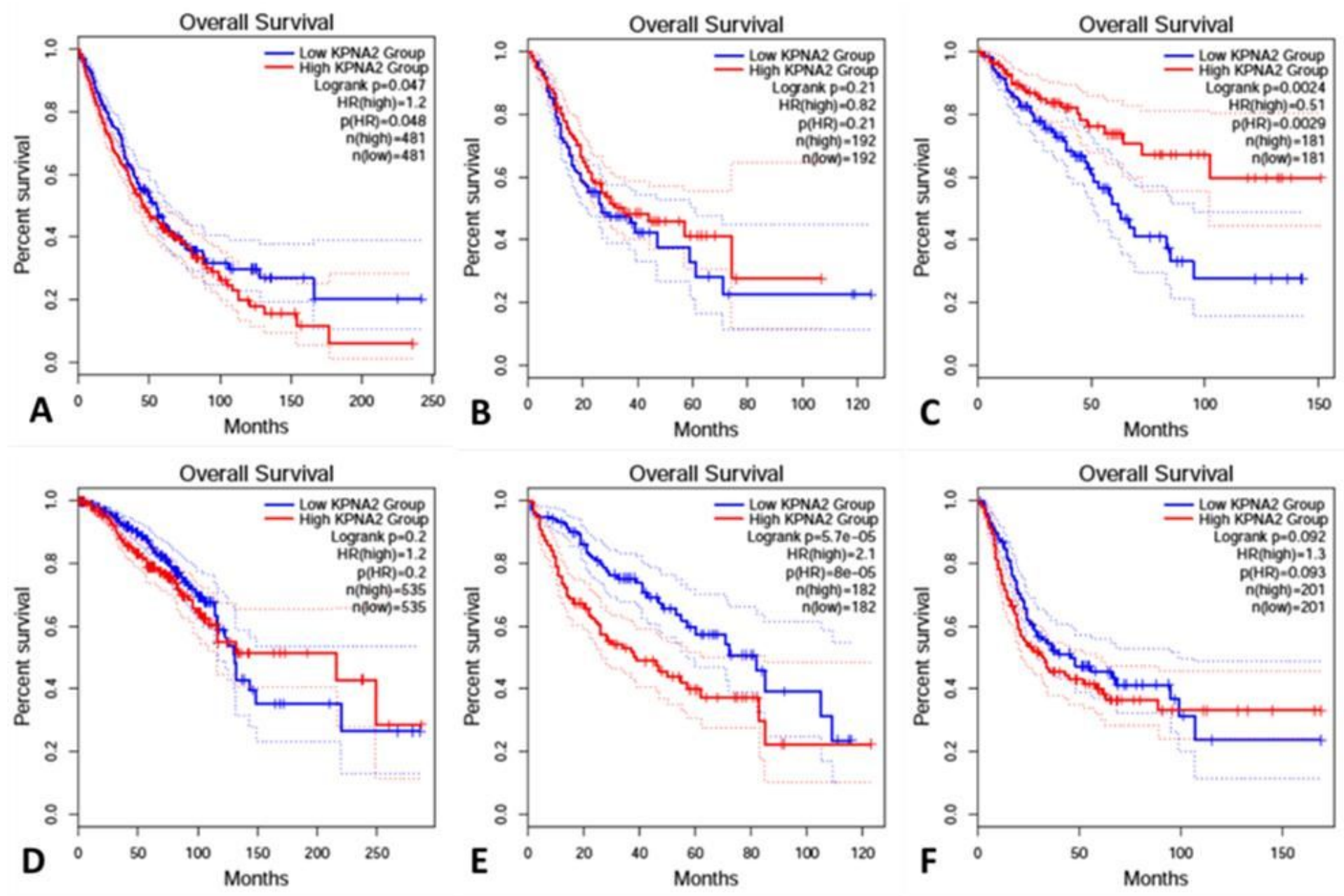

Figure 10

Overall survival (OS) between KPNA2 between high and low expression groups in 6 major cancers(A: NSCLC; B:gastric cancer; C: colorectal cancer; D: breast cancer; E: liver hepatic cancer; F:bladder cancer) 

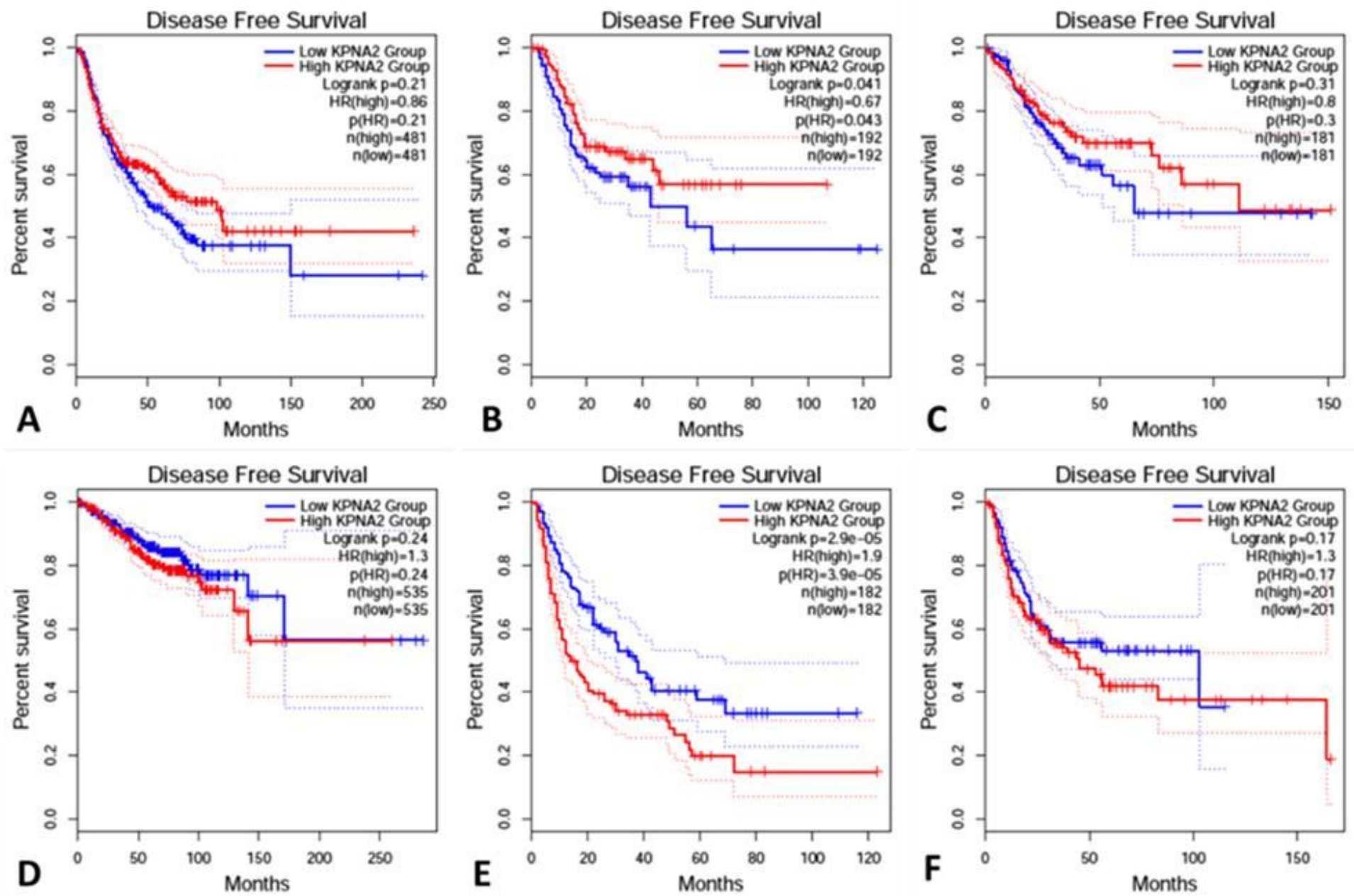

Figure 11

Disease free survival (DFS) between KPNA2 between high and low expression groups in 6 major cancers(A: NSCLC; B:gastric cancer; C: colorectal cancer; D: breast cancer; E: liver hepatic cancer; F:bladder cancer) 

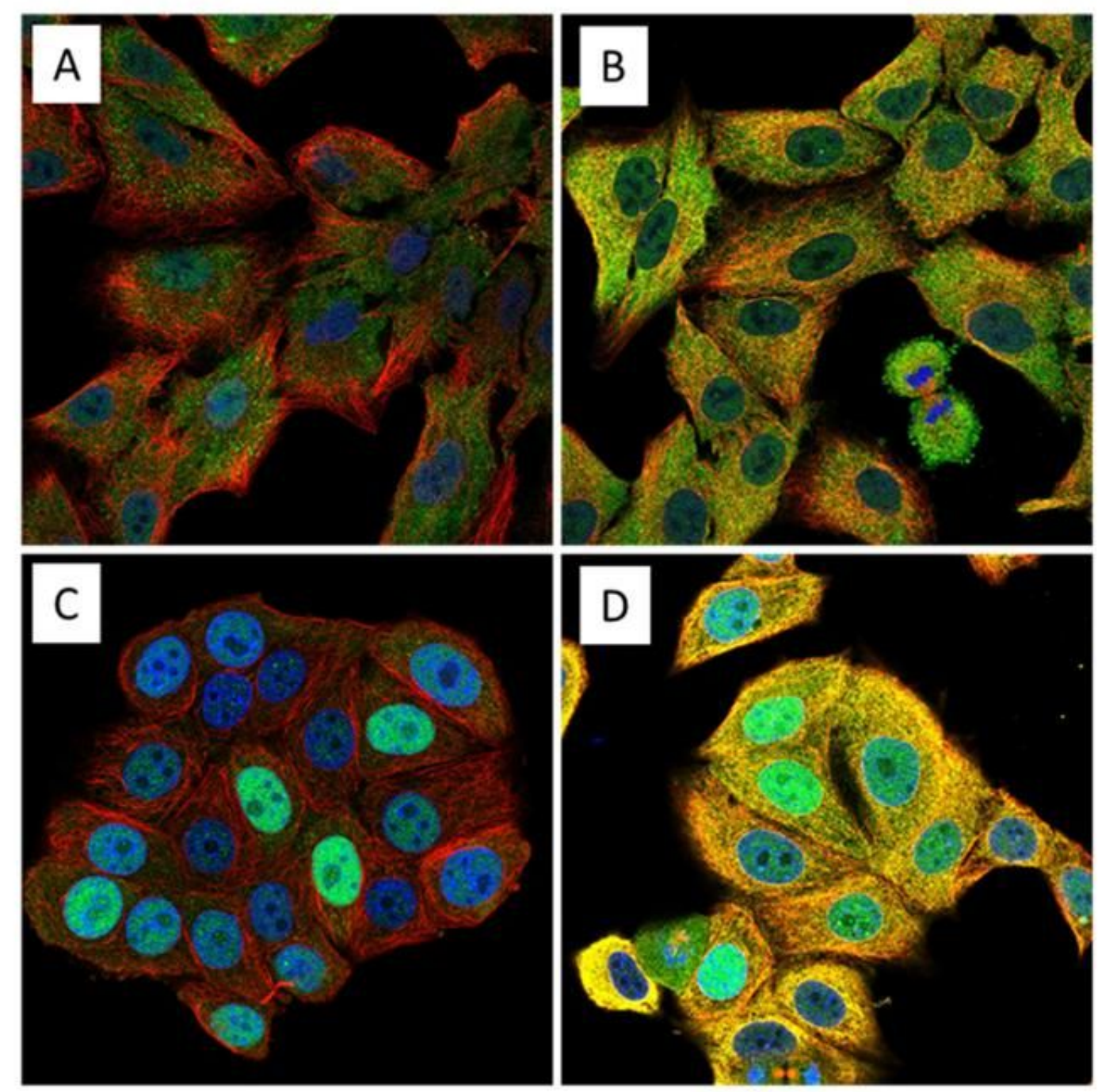

\section{Figure 12}

KPNA2 protein was mainly localized to the nucleoplasm and cytosol in cancer cells with blue staing (A: Immunofluorescent staining of human lung cancer cell line A549 shows localization to nucleoplasm in antibody+nucleus+microtubule channels; B: A: Immunofluorescent staining of human lung cancer cell line A549 shows localization to nucleoplasm in antibody+nucleus+microtubule+ER channels; C: Immunofluorescent staining of human breast cancer cell line MCF7 shows localization to nucleoplasm in antibody+nucleus+microtubule channels; D Immunofluorescent staining of human breast cancer cell line MCF7 shows localization to nucleoplasm in antibody+nucleus+microtubule+ER channels) 

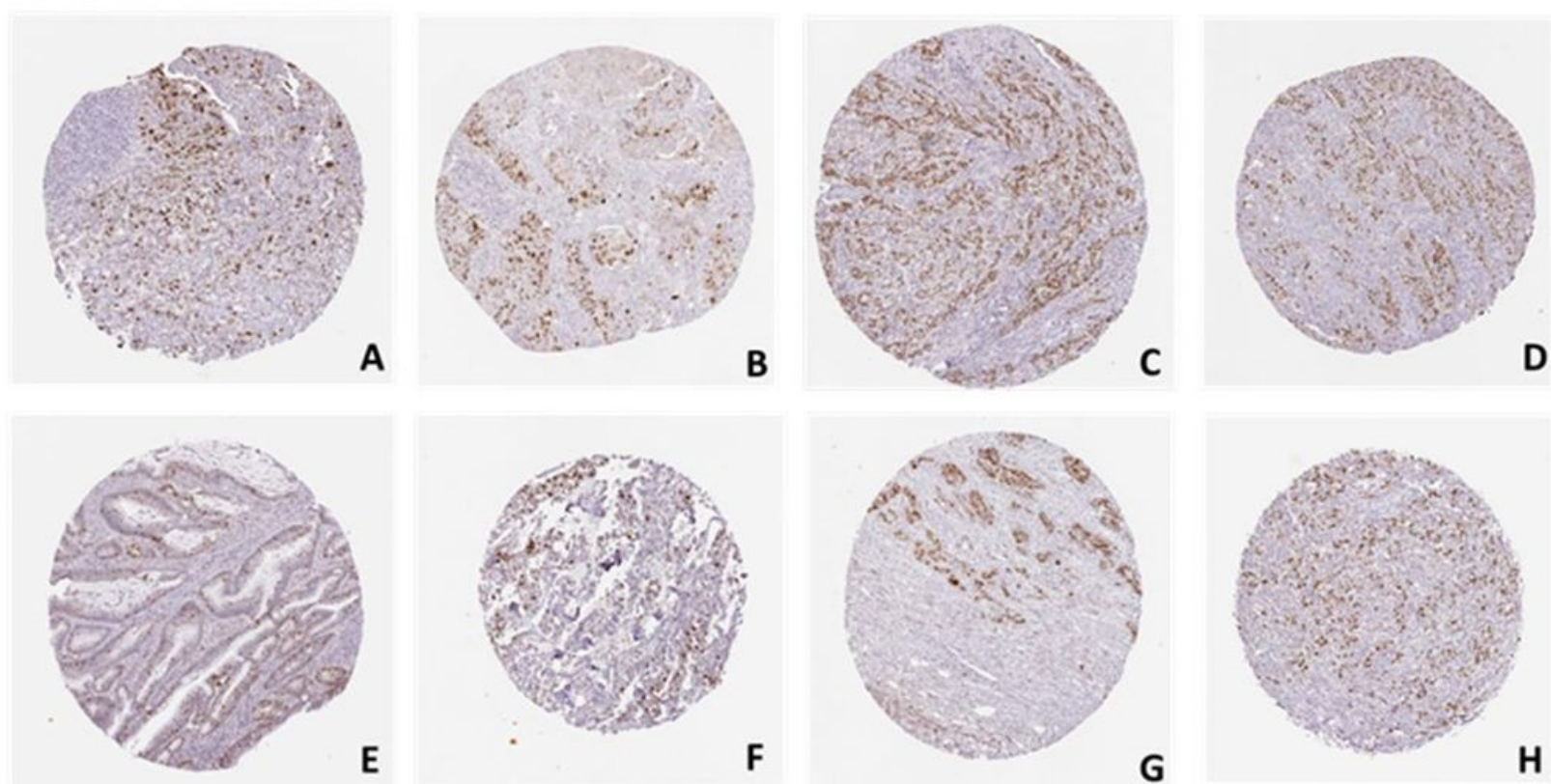

E

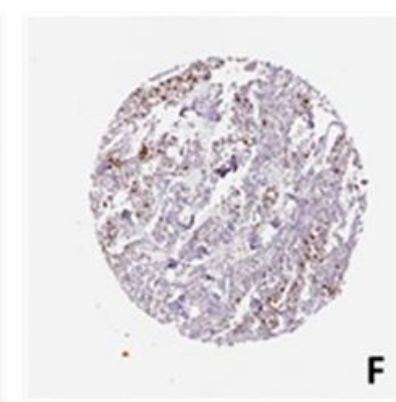

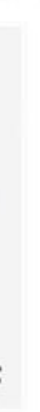
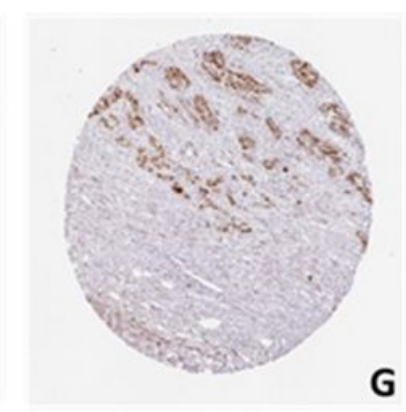

G

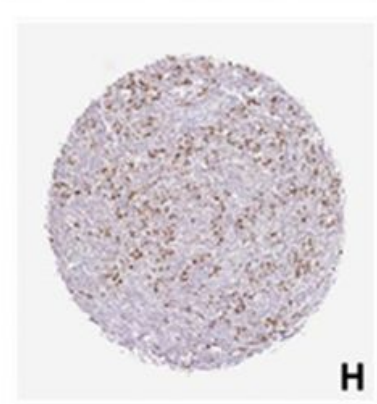

\section{Figure 13}

KPNA2 protein positive expression in 6 major cancers detected by Immunohistochemistry assay (A: lung adenocarcinoma; B: lung squamous cell carcinoma; C:gastric cancer; D:colon cancer; E: rectal cancer; F:breast cancer; G:liver hepatic carcinoma; H:bladder cancer) 
A

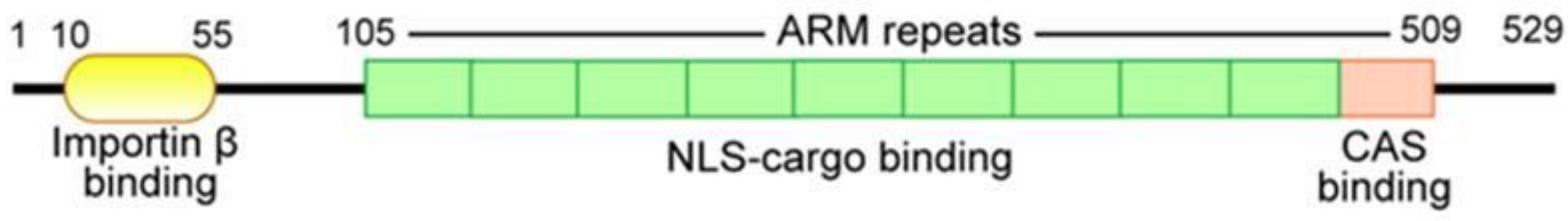

B

\section{Cytoplasm}

\section{Nucleus}

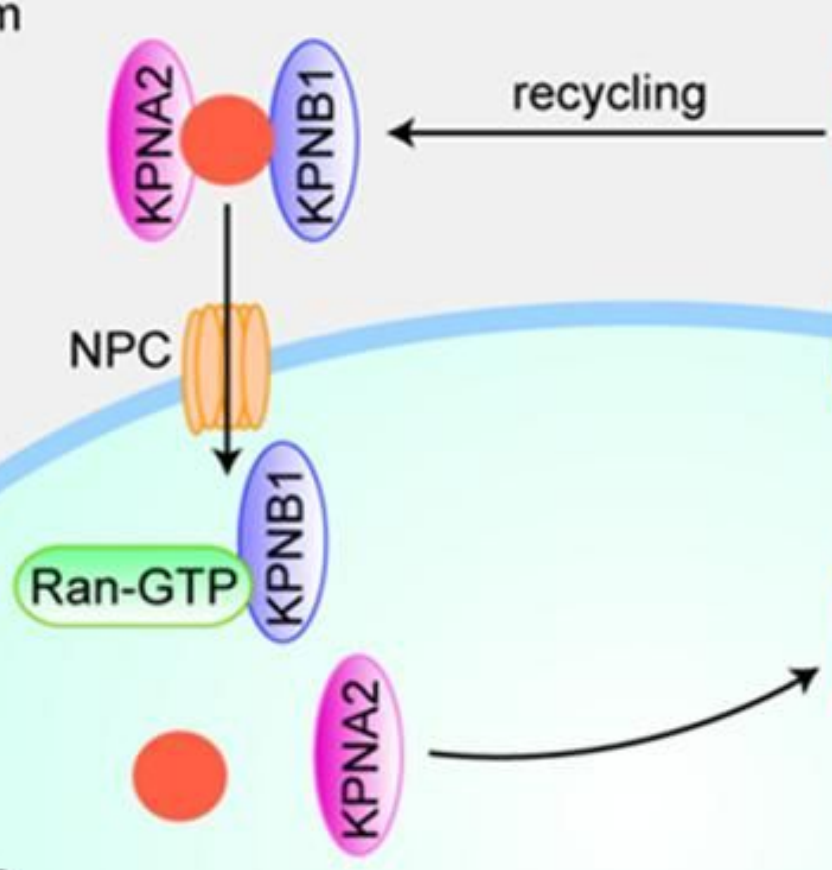

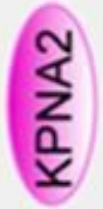
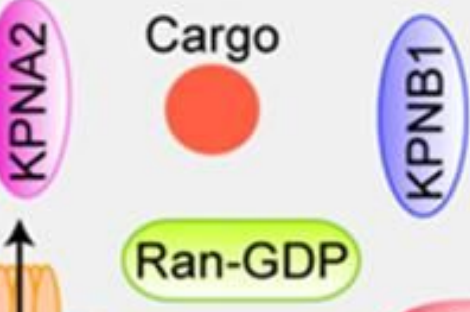

CAS

Ran-GTP

\section{Figure 14}

A diagrammatic representation of KPNA2 protein structure $(A)$ and the molecular mechanism of KPNA2 nucleoplasmic recirculation (B). (A) The N-terminus is the Importin $\beta$ (KPNB1) binding domain, ensuring that KPNA2 can only be translocated into the nucleus while simultaneously combining KPNB1 and cargo protein. The central region consists of 10 armadillo (ARM) repeats, including two NLS-cargo binding sites. The last ARM repeat mediates CAS binding. (B) KPNB1 brings a complex of KPNA2 and Cargo protein into the nucleus via NPC and binds to RanGTP to release KPNA2 and cargo proteins into the nucleus. Then KPNB1 returns directly to the cytoplasm. KNPA2 returns to the cytoplasm with the help of another transporter, CAS, for the next cycle. 